SÁNCHEZ-OSTIZ, Pablo "Imputación e incumbencias en Derecho penal".

Polít. crim. Vol. 12, № 24 (Diciembre 2017), Art. 15, pp. 1211-1227.

[http://www.politicacriminal.cl/Vol_12/n_24/Vol12N24A15.pdf]

\title{
Imputación e incumbencias en Derecho penal
}

\section{Imputation and concerns in Criminal law}

\author{
Pablo Sánchez-Ostiz \\ Catedrático de Derecho penal. Universidad de Navarra \\ pablosostiz@unav.es
}

\section{Resumen}

La categoría de las incumbencias despliega en Derecho penal un relevante papel en sede de imputación extraordinaria, en la medida en que, por un lado, puede contribuir a fundamentar la responsabilidad del agente por sus propios defectos de imputación (errores vencibles de tipo y prohibición, inimputabilidad...). Además, por otro lado, explica cómo operan las normas respecto a los destinatarios, quienes han de concretar el mensaje directivo recibido en su situación singular. Las incumbencias se diferencian de otras categorías próximas como el deber de cuidado, la idea de competencia, la obligación de conocer el Derecho y el concepto de deber.

Palabras clave: deberes, imputación extraordinaria, imputación, incumbencia, regla, responsabilidad.

\begin{abstract}
The concept of "concern" (incumbencia; german: "Obliegenheit") can be used in Criminal Law with an important role. Specially to define the extraordinary imputation ("imputación extraordinaria"; german: "außerordentliche Zurechnung"). The concept of concerns or "incumbencias" plays a important role to establish the liability of the agent for his own defects of imputation (mistakes of fact, mistakes of law, excuses...). In addition it explains how the rules operate into the recipients, who have to concretize the directive message received in their singular situation. However the concerns or "incumbencias" differ from other nearby categories such as the duty of care, the competence, the obligation to know the Law and the concept of duty.
\end{abstract}

Key words: concern, extraordinary imputation, imputation, legal duties, rule, strict liability.

Esta contribución tiene por objeto exponer la categoría de las incumbencias y la función que pueden cumplir en la imputación en Derecho penal ${ }^{1}$. Se trata de describir el

\footnotetext{
${ }^{1}$ La categoría ha sido tratada, en la doctrina penal en nuestro ámbito por MAÑALICH, Juan Pablo, Nötigung und Verantwortung. Rechtstheoretische Untersuchungen zum präskriptiven und adskriptiven Nötigungsbegriff im Strafrecht, Baden-Baden: Nomos, 2009, pp. 67-74; MONTIEL, Juan Pablo, "Obliegenheiten im Strafrecht?”, ZStW 129 (2014), pp. 592-614; MONTIEL, Juan Pablo, “¿Existen las Obliegenheiten en el Derecho penal?", InDret Penal 4/2014, pp. 1-29; SÁNCHEZ-OSTIZ, Pablo, "Existencia y operatividad de las
} 
SÁNCHEZ-OSTIZ, Pablo "Imputación e incumbencias en Derecho penal”.

fundamento y razón de ser de una categoría sobre la que se discute en la doctrina jurídicopenal en tiempos recientes. Afecta sin duda a la culpabilidad, pero también a la estructura de la actio libera in causa, así como a los errores vencibles, sean de tipo, sean sobre la antijuricidad.

La tesis que defiendo en esta contribución es que, además de las categorías de norma y deber, es conveniente tener en cuenta la de incumbencia. En particular, es relevante recurrir a la idea de incumbencia en los grupos de casos que se estudian bajo la denominación de actio libera in causa. Mi exposición se estructura en cuatro partes: primero se describe el uso que de las incumbencias se hace en la teoría del delito (1.), para de ahí señalar la ubicación sistemática que me parece adecuada (2.) y describir su operatividad (3.); finalmente, se distinguen las incumbencias de otras categorías próximas como las deber de cuidado, competencia, obligación de conocer la ley y deber.

\section{El recurso a las incumbencias en la teoría del delito}

En la literatura jurídico-penal de la teoría del delito se recurre en los últimos años a la idea de incumbencia para referirse a peculiares deberes, cargas u obligaciones. Por un lado, para calificar ciertas cargas u obligaciones de autoprotección de la propia víctima del delito². Por otro lado, también se recurre a la idea de (infracción de) incumbencias en los ámbitos de la tentativa $^{3}$, o de la participación ${ }^{4}$. Además, para definir las obligaciones que recaen sobre personas jurídicas con el fin de implantar compliance programs ${ }^{5}$. En un ámbito más

incumbencias jurídico-penales”, en: CARNEVALI RODRÍGUEZ, Raúl, (Ed.), Derecho, sanción y justicia penal, Montevideo, Buenos Aires: BdeF, 2017, pp. 41-59; SÁNCHEZ-OSTIZ, Pablo, "¿Incumbencias en Derecho penal?.-Depende", InDret Penal 1/2015, pp. 1-27 (que constituye una respuesta al último de los trabajos citados de Montiel); SÁNCHEZ-OSTIZ, Pablo, La libertad del Derecho penal y otros estudios sobre la doctrina de la imputación, Barcelona: Atelier, 2014, pp. 139-159; SÁNCHEZ-OSTIZ, Pablo, Imputación y teoría del delito. La doctrina kantiana de la imputación y su recepción en el pensamiento jurídico-penal contemporáneo, Montevideo, Buenos Aires: BdeF, 2008, pp. 532-555.

${ }^{2}$ Cfr. JAKOBS, Günther, Strafrecht. Allgemeiner Teil. Die Grundlagen und die Zurechnungslehre, 2. ${ }^{\mathrm{a}}$ ed, Berlín, Nueva York: Gruyter, 1991, 7/56-68; 24/16-21; también WOLTER, Jürgen, Objektive und personale Zurechnung von Verhalten, Gefahr und Verletzung in einem funktionalen Straftatsystem, Berlín: Duncker \& Humblot, 1981, pp. 342-349; FRISCH, Wolfgang, Tatbestandsmäßiges Verhalten und Zurechnung des Erfolgs, Heidelberg: C.F. Müller, 1988, pp. 450-455. Y en el marco más amplio del "principio de autoprotección" de la víctima, HÖRNLE, Tatjana, "Die Obliegenheit, sich selbst zu schützen, und ihre Bedeutung für das Strafrecht”, GA 2009, pp. 626-635, 628-632.

${ }^{3}$ Cfr. JAKOBS, Günther, System der strafrechtlichen Zurechnung, Fráncfort d.M.: Klostermann, 2012, p. 70, en la medida en que la sanción por la ejecución no seguida de resultado es contraria a lo que incumbe y no propiamente a la norma (no consumado el tipo).

${ }^{4}$ En concreto, para la participación en fase previa o preparatoria: cfr. JAKOBS, System der Strafrechtlichen Zurechnung, cit. nota $\mathrm{n}^{\circ}$ 3, pp. 70, 79 y 91; JAKOBS, Günther, Theorie der Beteiligung, Tubinga: Mohr Siebeck, 2014, pp. 18, 45, pero en un sentido diverso al que se da en esta contribución: "Diese Zurechnung des Unrechts erfolgt nicht außerordentlich, da bei der Schaffung des Zurechnungsgrundes (bei der Obliegenheitsverletzung) kein Zurechnungsdefekt vorliegen darf, die subjektive Seite also komplett gegeben sein muss, nur eben auf die Verletzung einer ,Pflicht gegen sich selbst' bezogen." (p. 18).

${ }^{5}$ En este sentido, ROBLES PLANAS, Ricardo, "El "hecho propio" de las personas jurídicas y el Informe del Consejo General del Poder Judicial al Anteproyecto de Reforma del Código Penal de 2008”, InDret Penal 2/2009, pp. 1-12, 10; ROBLES PLANAS, Ricardo, Estudios de dogmática jurídico-penal. Fundamentos, teoría del delito y Derecho penal económico, Montevideo, Buenos Aires: BdeF, 2014, p. 220, n. 37, 226-227, 
Polít. crim. Vol. 12, № 24 (Diciembre 2017), Art. 15, pp. 1211-1227.

[http://www.politicacriminal.cl/Vol_12/n_24/Vol12N24A15.pdf]

general, se recurre a la expresión para mencionar las cargas que sobre el ciudadano recaen con el fin de precisar la concreta norma de acción en el caso singular ${ }^{6}$. De manera más concreta, las incumbencias pertenecen al ámbito de la imputación al sujeto de sus propios defectos ${ }^{7}$. En mi opinión, este último es el principal ámbito en el que tiene sentido referirse a incumbencias en Derecho penal. Más en concreto, se trata de la "imputación extraordinaria", según la denominación que en su momento le dio Hruschka8 .

A pesar de esta restricción, la asociación de ideas entre incumbencias y esos diversos Topoi (autorresponsabilidad de la víctima, tentativa, participación, obligación de implantar compliance programs, responsabilidad por defectos de imputación y obligaciones para el ciudadano) destaca que las incumbencias tienen relación con ciertas cargas que corresponden a los destinatarios de normas. Se trata de ámbitos de obligación en los que apreciamos una menor intensidad que en otros sectores: una suerte de obligación de menor entidad, débil, o funcional, en cuanto encaminada a determinar y precisar otra obligación, que sería de carácter "fuerte", en cuanto claramente expresada. Además, en tales casos se espera una conducta del destinatario de la norma para conocerla o concretarla, pero dicho destinatario goza de un amplio margen de libertad de acción, y no encuentra delimitado hasta el detalle su ámbito de actuación; al contrario, se espera que sea él quien detalle la norma de conducta, que haga algo de su parte para precisar el concreto comportamiento a realizar. También se percibe en tales casos un modo de proceder en la selección de normas que responde a la idea de subsidiariedad, es decir, a la prelación de una obligación sobre otra, cuya vigencia estaría condicionada por la de la primera ${ }^{9}$.

Sin embargo, pienso que el empleo de la expresión y concepto de incumbencia en todos esos ámbitos no resulta plenamente adecuado, ya que no aporta un significado específico y bien definido, por lo que puede oscurecer el sentido que posee en otras categorías. En tales

236-237, 262; COCA VILA, Ivó, “¿Programas de Cumplimiento como forma de autorregulación regulada?”, en: SILVA SÁNCHEZ, Jesús-María (Dir.); MONTANER FERNÁNDEZ, Raquel (Coord.), Criminalidad de empresa y Compliance. Prevención y reacciones corporativas, Barcelona: Atelier, 2013, p. 55.

6 Así, PAWLIK, Michael, Das Unrecht des Bürgers. Grundlinien der Allgemeinen Verbrechenslehre, Tubinga: Mohr Siebeck, 2012, pp. 259, 345, 354, 375, entre otros lugares.

7 Así, en concreto, crítico, MONTIEL, "Obliegenheiten im Strafrecht?", cit. nota no 1, pp. 592-614. Cfr. ibidem, 596-598, la descripción detallada del recurso -,,inflationäre Verwendung”, p. 596- en la doctrina penal al concepto de incumbencia.

${ }^{8}$ En efecto, el concepto y la expresión se deben a HRUSCHKA, Joachim, Strafrecht nach logischanalytischer Methode, $2^{a}$ ed., Berlín, Nueva York: Gruyter, 1988, pp. 274-386. Cfr. la valoración que efectúa NEUMANN, Ulfrid, "Normtheorie und strafrechtliche Zurechnung", GA 1985, pp. 389-401. Sobre el origen y evolución de la figura en su planteamiento, cfr. SÁNCHEZ-OSTIZ, Imputación y teoría del delito, cit. nota $\mathrm{n}^{\circ}$ 1 , pp. 533-534, n. 87, con referencias.

${ }^{9}$ En este punto, expresa MONTIEL, “Obliegenheiten im Strafrecht?”, cit. nota ${ }^{\circ}{ }^{1}$, p. 612: „So sollte m.E. etwa die deontische Entität, die bei der sog. ,außerordentliche Zurechnung' verletzt wird, als subsidiäre Pflicht gekennzeichnet werden, also als Unterart der Nebenpflichten”. Sin embargo, en mi opinión, así se corre el riesgo de entender que algunos preceptos de la legislación penal serían expresión de imputación extraordinaria, cuando en realidad supondrían una extensión conceptual indebida (supuestos de actio illicita in causa, en los que el legislador condiciona la aplicación de la causa de justificación a que la situación no haya sido provocada): se trata de determinar la norma aplicable para la valoración de un hecho u omisión, y no de un caso de imputación. Por lo tanto, tampoco de imputación extraordinaria. Cfr. NEUMANN, "Normtheorie und strafrechtliche Zurechnung", cit. nota no 8, pp. 391-393, 400-401. 
SÁNCHEZ-OSTIZ, Pablo "Imputación e incumbencias en Derecho penal".

casos, pienso que sería suficiente recurrir a ideas como las de deberes indirectos ${ }^{10}$, cuasinormas ${ }^{11}$, normas de contenido débil, obligaciones respecto a uno mismo; o prever una nueva y específica terminología. Sin perjuicio de que exista algún punto de conexión conceptual, la idea aquí expuesta es distinta de la empleada en materia de autorresponsabilidad de la víctima, tentativa, participación o la obligación de implantar compliance programs. Se aproxima al sentido que le otorgan algunos autores para referirse a la carga que sobre el ciudadano recae para concretar la norma de acción. Y sobre todo, se mueve en el ámbito de la responsabilidad por defectos de imputación ${ }^{12}$.

\section{Ubicación adecuada de las incumbencias}

A mi modo de ver, su adecuada ubicación se halla en los juicios u operaciones de imputación y, en concreto, la de carácter extraordinario ${ }^{13}$. La imputación extraordinaria opera en aquellos supuestos en los que un defecto en el sujeto impide la imputación (ordinaria). Así, en lugar de ésta, la imputación extraordinaria impide que dicho defecto excluya la responsabilidad. Se mantiene o restablece la imputación a pesar de - ¿o precisamente por?- ese defecto. Es decir, hacemos responsable al propio sujeto del defecto en cuestión. Como modo de proceder, la idea ya estaba en autores antiguos cuando se planteaban la responsabilidad por los propios defectos ${ }^{14}$, y es el ámbito propio de la imprudencia, los errores vencibles, así como la responsabilidad por la propia inimputabilidad o, de manera más general, la actio libera in causa, y la omissio libera in causa.

Esta vía extraordinaria de imputación pone de manifiesto que la imputación se mantiene "a pesar de", razón por la que podrían denominarse también reglas "adversativas" de imputación, frente a las de la imputación ordinaria o reglas "consecutivas" 15 . Dichas reglas adversativas se basan en la desvaloración que merece ese defecto de imputación del agente $^{16}$. La intolerabilidad del defecto activa las reglas adversativas para restablecer la

${ }^{10}$ Como „teleologische Ableitungen aus Verursachungsnormen“ en: AST, Stephan, Normentheorie und Strafrechtsdogmatik. Eine Systematisierung von Normarten und deren Nutzen für Fragen der Erfolgszurechnung, insbesondere die Abgrenzung des Begehungs- vom Unterlassungsdelikt, Berlín: Duncker \& Humblot, 2010, p. 47.

${ }^{11}$ Esta expresión, en: PHILIPPS, Lothar, "Normentheorie", en: KAUFMANN, Arthur; HASSEMER, Winfried; NEUMANN, Ulfrid (Eds.), Einführung in Rechtsphilosophie und Rechtstheorie der Gegenwart, $7^{\text {a }}$ ed., Heidelberg: Müller, 2004, pp. 331-332.

${ }^{12}$ En el sentido de las aportaciones de MONTIEL: cfr. supra, nota $\mathrm{n}^{\circ} 7$.

${ }^{13}$ Cfr. supra, nota ${ }^{\circ} 8$.

${ }^{14}$ Cfr. HRUSCHKA, Joachim, "Ordentliche und außerordentliche Zurechnung bei Pufendorf. Zur Geschichte und zur Bedeutung der Differenz von actio libera in se und actio libera in sua causa", ZStW 96 (1984), pp 661-702 (trad. Pastor Muñoz, en: Imputación y Derecho penal. Estudios sobre la teoría de la imputación, Cizur Menor (Navarra): Thomson-Aranzadi, 2005, pp. 55-88), pp. 661-702; SÁNCHEZ-OSTIZ, La libertad del Derecho penal, cit. nota no 1, pp. 119-134.

${ }^{15}$ Cfr. la terminología que propone SÁNCHEZ-OSTIZ, Imputación y teoría del delito, cit. nota ${ }^{\circ} 1$, p. 36, 534. NEUMANN, "Normtheorie und strafrechtliche Zurechnung", cit. nota $\mathrm{n}^{\circ}$ 8, p. 391, se refiere a „Ausnahmeregeln“".

${ }^{16}$ A la cuestión de si se trata de una regla de conducta, o en cambio de una regla de imputación me he referido en otros lugares. Las primeras expresan cómo hay que actuar (prohibiciones, prescripciones y facultades), 
Polít. crim. Vol. 12, № 24 (Diciembre 2017), Art. 15, pp. 1211-1227.

[http://www.politicacriminal.cl/Vol_12/n_24/Vol12N24A15.pdf]

imputación; es decir, para mantener la imputación a pesar del defecto. Esta es la consecuencia principal de la infracción de una incumbencia ${ }^{17}$.

Como consecuencia de la infracción de una incumbencia, se restablece la imputación ${ }^{18}$. Puesto que se trata de imperativos de carácter hipotético ${ }^{19}$, la incumbencia incorpora una condición que se convierte en razón externa para actuar. Aquí no se trata del anuncio de una pena por su infracción, sino de la consecuencia de que la imputación no va a verse impedida $^{20}$. Y ello por cuanto forma parte de nuestras representaciones sociales y el modo propio de entendernos que la atribución de responsabilidad solo procede cuando el sujeto sabe y controla lo que sabe, es decir, cuando hay conocimiento y voluntad. Por tanto, el presupuesto de aplicación de una incumbencia rezaría así: "si eres destinatario de una norma, preocúpate de conocer el concreto deber y las circunstancias del caso, así como de mantenerte en disposición de poder cumplirlo, porque, si no, ...”; y la consecuencia: “... se te imputará igualmente". Esto supone aceptar que la norma, per se, no es apta para la acción hasta que el destinatario conoce su contenido y se lo aplica a su caso concreto. Es decir, que las normas no existen si no en el mundo de los destinatarios racionales; y aquí, como enunciados que han de ser actualizados en el razonamiento práctico. Por eso, se precisa conocer tanto las normas como las circunstancias fácticas para su aplicación. Se podría decir, de manera en cierto modo provocadora, que es antes la imprudencia que la conducta dolosa, pues primero se espera del sujeto destinatario de la norma que la conozca

frente a las segundas, que indican lo requerido para atribuir algo como un hecho y un hecho antijurídico a título de reproche a su artífice.

17 Crítico con la capacidad de rendimiento del concepto de incumbencia, FRISCH, Wolfgang, "Grundprobleme der Bestrafung ,,verschuldeter" Affekttaten. Eine dogmatische Zwischenbilanz aus Anlaß neuerer Entwicklungen”, ZStW 101 (1989), pp. 579-584.

${ }^{18}$ Sobre esta cuestión, cfr. SANCHEZ-OSTIZ, “IIncumbencias en Derecho penal?.-Depende”, cit. nota $\mathrm{n}^{\mathrm{o}} 1$, 20-21; SANCHEZ-OSTIZ, La libertad del Derecho penal, cit. nota ${ }^{\circ}$ 1, pp. 155, 157-158.

${ }^{19}$ La afirmación de HRUSCHKA, Joachim, "Über Tun und Unterlassen und über Fahrlässigkeit", en: KAUFMANN, Arthur et al. (Eds.), Festschrift für Paul Bockelmann zum 70. Geburtstag, Múnich: Beck, 1979, pp. 421 (422, 426), según la cual las incumbencias responden a imperativos hipotéticos (y no categóricos), se entiende en el sentido de que para poder cumplir una norma es condición reunir -y mantener- la capacidad de realizar lo exigido (cfr. RUDOLPH, Tobias, Das Korrespondenzprinzip im Strafrecht. Der Vorrang von ex-ante Betrachtungen gegenüber ex-post Betrachtungen bei der strafrechtlichen Zurechnung, Berlín: Duncker \& Humblot, 2006, p. 82). Si se atiende a que dejar de actuar conforme a lo que incumbe al agente no lleva consigo una sanción (si no es a través de la consiguiente infracción en su caso del deber a que vaya asociada), entonces las incumbencias representan imperativos categóricos (así, en SEEBAß, Gottfried, "Handlungstheoretische Aspekte der Fahrlässigkeit", JRE 2 [1994], pp. 375-411, 403, nota 53); también si se entiende que las incumbencias expresan prohibiciones y prescripciones incondicionadas (así, BIEWALD, Günther, Regelgemäßes Verhalten und Verantwortlichkeit. Eine Untersuchung der Retterfälle und verwandter Konstellationen, Berlín: Duncker \& Humblot, 2003, p. 37, pero con la matización señalada ibidem en n 19, p. 108). Por mi parte, en la medida en que las incumbencias se refieren a la posibilidad de cumplir un deber, encierran imperativos de carácter hipotético, pero no porque lleven consigo una sanción condicionada a su "incumplimiento", sino porque son condición para cumplir el deber cuya efectividad vienen a garantizar.

${ }^{20}$ Para NEUMANN, "Normtheorie und strafrechtliche Zurechnung", cit. nota $\mathrm{n}^{\text {o }}$ 8, p. 392, "Die Verletzung einer Obliegenheit ist selbst noch keine Verletzung einer Rechtspflicht, rechtfertigt als solche keinen strafrechtlichen Vorwurf; sie hat aber die Konsequenz, daß der Täter sich nicht zu seiner Verteidigung auf die obligationswidrig herbeigeführte Situation berufen kann.” 
SÁNCHEZ-OSTIZ, Pablo "Imputación e incumbencias en Derecho penal”.

y concrete en deber, y solo después viene la conducta dolosa contraria ${ }^{21}$. Expresado ahora de manera funcional: así como el deber sigue a la norma en el orden de la formulación, la incumbencia precede al deber en el orden de la acción. De este modo, aparece claro que la consecuencia por el incumplimiento de la incumbencia no es la imposición de una sanción en sentido estricto - de una pena o similar-22, sino el restablecimiento de la imputación que se vio inicial, pero provisionalmente interrumpida por el defecto de imputación.

En cambio, la infracción de una incumbencia no implica necesariamente la atenuación de la pena. Esto sucede cuando a continuación se procede a aplicar un tipo imprudente cuya pena sea menor. Pero sucede también que algunos "errores" (esto es, defectos de imputación) resultan tan intolerables que no estamos dispuestos a atenuar la pena: así, en aquellos casos de dolo eventual en los que el agente conoce que no controla la situación y, aun así, actúa; o que conoce que carece de conocimientos que la situación requiere y, a pesar de eso, continúa obrando. En sede de desconocimiento de la antijuricidad, su operatividad es semejante: no siempre la infracción de la incumbencia lleva consigo atenuación de la pena. La operatividad de las incumbencias, por tanto, no es atenuar la sanción ${ }^{23}$, y no pueden tomarse como vías de atenuación de la pena (lo cual es más claro en códigos penales que prevén una atenuación facultativa, pero también en los de atenuación preceptiva puede suceder que el desconocimiento se tome como irrelevante en ciertos casos). Y menos todavía como recursos para defender una consecuencia penal cuando se carece de la base necesaria para atribuir responsabilidad, eludir una laguna legal, o suplir un defecto de la ley ${ }^{24}$.

Una dificultad para asumir la categoría de las incumbencias ha sido la de su origen civilista, de Derecho privado ${ }^{25}$. Sin embargo, entiendo que el tratamiento de las incumbencias en Derecho civil no condiciona su sentido y operatividad, pues considero que no estamos ante la faceta penal de una institución jurídico-civil. Tendrían en común con el uso del concepto en Derecho civil que suponen una carga para la persona como condición para aspirar a una

${ }^{21}$ Cfr. ROSTALSKI, Frauke, "Normentheorie und Fahrlässigkeit. Zur Fahrlässigkeit als Grundform des Verhaltensnormverstoßes", GA 2016, pp. 73-89 (73, 80, 82, 89). Mi posición, sin embargo, difiere de la expuesta por esta autora (84-88) sobre la precedencia del tipo imprudente.

${ }^{22}$ Como expresa HRUSCHKA, Strafrecht, cit. nota $\mathrm{n}^{\circ}$ 8, p. 416, "Nur die Verletzung von (Rechts-)Pflichten wird bestraft, während die Verletzung von Obliegenheiten als solche straflos ist."

${ }^{23}$ De tal manera que es posible imputar por vía extraordinaria, y después considerar el hecho como tipo doloso eventual: así, en caso de errores burdos (que pueden ser errores en sentido literal), o de ceguera ante los hechos (cfr. SANCHEZ-OSTIZ, La libertad del Derecho penal, cit. nota $\mathrm{n}^{\circ}$ 1, pp. 94, 97, 157-158).

${ }^{24}$ A esto debe unirse las respuestas a las críticas habituales a la imputación extraordinaria basada en el modelo de la excepción (recuérdese: no respetar los "principios" de legalidad, tipicidad y culpabilidad, y el criterio de congruencia): cfr. SANCHEZ-OSTIZ, La libertad del Derecho penal, cit. nota $\mathrm{n}^{\circ}$ 1, pp. 146-149, 156.

${ }^{25}$ Cfr. la crítica de MONTIEL, “Obliegenheiten im Strafrecht?", cit. nota ${ }^{\circ}$ 1, pp. 599-604. Cfr. también TOEPEL, Friedrich, Kausalität und Pflichtwidrigkeitszusammenhang beim fahrlässigen Erfolgsdelikt, Berlín: Duncker \& Humblot, 1992, pp. 38-39; RENZIKOWSKI, Joachim, Restriktiver Täterbegriff und fahrlässige Beteiligung, Tubinga: Mohr Siebeck, 1997, p. 220, n. 42; HAAS, Volker, Kausalität und Rechtsverletzung. Ein Beitrag zu den Grundlagen strafrechtlicher Erfolgshaftung am Beispiel des Abbruchs rettender Kausalverläufe, Berlín: Duncker \& Humblot, 2002, p. 80. El propio HRUSCHKA, Strafrecht, cit. nota ${ }^{\circ} 8$, p. 416, previene de su uso en el mismo sentido que el habitual en Derecho de seguros, en donde significa incurrir en una obligación contra sí mismo (cfr. el planteamiento desarrollado por BIEWALD, Regelgemäßes Verhalten und Verantwortlichkeit, cit. nota $\mathrm{n}^{\circ} 19$, pp. 105-106). 
Polít. crim. Vol. 12, № 24 (Diciembre 2017), Art. 15, pp. 1211-1227.

[http://www.politicacriminal.cl/Vol_12/n_24/Vol12N24A15.pdf]

pretensión. Pero obsérvese que, en el uso que aquí se da al concepto la incumbencia, es una condición para que la norma penal sea efectiva, y no para el ejercicio de una pretensión. Podría considerarse como "pretensión" del agente la de no ser sancionado por un defecto de imputación; sin embargo, la incumbencia logra, más que impedir la aplicación de la ley, que ésta se cumpla. En definitiva, el concepto admite una construcción propiamente jurídico-penal, como ya ha sucedido con otras categorías. Piénsese, por ejemplo, en el concepto de dolo (en donde nadie plantea retornar a sus orígenes en los vicios del consentimiento de doctrina de las obligaciones), pero algo semejante cabría decir de la idea de causalidad e imputación objetiva (materia en donde los avances de la doctrina jurídicopenal son enormes) $)^{26}$.

\section{Función de las incumbencias}

En el planteamiento ahora descrito sobre la imputación extraordinaria la norma de conducta expresa un mensaje que se hace operativo por obra de un sujeto destinatario. Este sujeto no sólo es receptor del mensaje, sino también contribuye a concretarlo. Y en esta medida, puede verse como co-configurador de la norma de acción. El sujeto destinatario contribuye a configurar la norma - no me refiero a que intervenga mediata o inmediatamente en su elaboración-, en cuanto que la concreta en deber, y hace así posible y real el mensaje contenido en aquella. Este planteamiento resulta asumible si atendemos a que el sujeto destinatario de la norma, al emplear esta para su caso particular, y llegar a una concreta orden de acción u omisión, interviene en un proceso de determinación del mensaje normativo que requiere contar con los datos de la situación en la que se halla. De este modo, al pasar de la norma general a la acción concreta, ejerce la norma su función configuradora de decisiones, de acciones singulares. En cierto sentido se podría hablar de un proceso de "autonomización" -mejor que "autonomía"-, en cuanto que el destinatario de esta llega a hacer suyo el mensaje expresado en la norma, que carecerá de fuerza deóntica real si no se plasma en deber ${ }^{27}$.

Para explicar este proceso de concreción, cabe distinguir tres niveles en un enunciado obligacional. En el plano más abstracto, contamos con la norma (prohibitiva, prescriptiva o permisiva); y en un nivel de "concreción para la acción" o de "regla de conducta", tanto el deber (sea una prohibición, sea una prescripción o mandato) como la permisión (facultad). La operatividad de las reglas de conducta entendidas como ámbitos de desarrollo personal presupone contar con un destinatario racional, al que concierne la ideación de su deber de acción particular. Me refiero a ideación, en cuanto proceso intelectual de determinación ${ }^{28}$; y a que es particular, en cuanto que es personal y para las concretas circunstancias del caso.

\footnotetext{
${ }^{26}$ Por otra parte, en opinión de SÁNCHEZ-OSTIZ, “¿Incumbencias en Derecho penal?.-Depende”, cit. nota $\mathrm{n}^{\mathrm{o}}$ 1, p. 7, lo esencial no es la traducción como incumbencia, siempre que exista un término mejor.

27 Dicho proceso de autonomización, de hacer suyo, no significa sin embargo que las valoraciones de la norma deban ser interiorizadas por el destinatario. Se trata de algo más simple: la norma no es tal sin la asunción por el destinatario como mensaje de acción; y esto es tarea suya.

${ }^{28}$ Soy consciente de que el término "ideación" no es usual. Con dicho concepto me refiero al proceso de abstracción de las circunstancias, como también de concreción de la norma, para llegar al deber o permisión en el caso concreto.
} 
SÁNCHEZ-OSTIZ, Pablo "Imputación e incumbencias en Derecho penal”.

El paso de la norma al deber (y a la permisión) requiere una actividad del destinatario, eventual agente. En concreto, se requiere extraer y formular ese deber (y la permisión, cuando proceda), porque las normas "no se concretan solas", o per se, sino que exigen una actividad intelectual, previa a la decisión volitiva por la acción, en la que se implica el propio destinatario de la norma ${ }^{29}$. Para ello, es útil contar con una categoría deóntica adicional, cuya función sea que el destinatario concrete el deber y pueda llegar a actuar. Surge entonces la idea de las "incumbencias". Por tanto, en sentido operativo o funcional, las incumbencias son instrumentos de concreción de la norma en deber ${ }^{30}$. Así, junto a los contenidos expresados como deber en la norma ("primarios"), existirían otros contenidos normativos ("secundarios") $)^{31}$, cuya finalidad y sentido consisten en hacer posible el cumplimiento de los primarios ${ }^{32}$. Se trataría de "normas" y de normas "jurídicas" 33 , y no meramente éticas ${ }^{34}$, como si fueran preceptos morales que entraran subrepticiamente en el ordenamiento jurídico.

Entiendo que las incumbencias presentan de una doble faceta. En concreto, y en la medida en que la norma es mensaje, se requiere de un destinatario que perciba esa comunicación, lo cual requiere conocerla, así como representarse las condiciones fácticas de aplicación: i) las incumbencias de conocer, referidas tanto a la norma ("está prohibido matar") como a los datos fácticos ("estoy manipulando un instrumento peligroso en un entorno en el que alguien puede resultar herido"); y, puesto que la norma aspira a configurar la acción, se

${ }^{29}$ En opinión de BINDING, Karl, Die Normen und ihre Übertretung, II-1, 2a ed, Leipzig, 1914; reimpr, Aalen: Scientia, 1991, p. 143, cabría pensar para tales casos en su sanción específica: „Ein solches Strafgesetz mit leichter Strafdrohung aber dürfte durchaus zweckmässig, ja unentbehrlich sein!".

${ }^{30} \mathrm{El}$ papel de las incumbencias en sede de causas de justificación, esto es, de normas facultativas, es algo que requiere un estudio aparte. No me refiero a la actio illicita in causa, tópico al que ya me he referido críticamente- en otros lugares como aparente caso de imputación extraordinaria -pues no lo es-, sino a la ideación de la facultad de obrar (como excepción al deber).

${ }^{31}$ Cfr. HRUSCHKA, "Über Tun und Unterlassen und über Fahrlässigkeit", cit. nota no 19, p. 426. Cfr. también RENZIKOWSKI, Restriktiver Täterbegriff, cit. nota $\mathrm{n}^{\circ}$ 25, p. 80; RUDOLPH, Das Korrespondenzprinzip im Strafrecht, cit. nota $\mathrm{n}^{\circ}$ 19, p. 90; HÜBNER, Christoph, Die Entwicklung der objektiven Zurechnung, Berlín: Duncker \& Humblot, 2004, p. 110. Contra, GÜNTHER, Klaus, Schuld und kommunikative Freiheit. Studien zur personalen Zurechnung strafbaren Unrechts im demokratischen Rechtsstaat, Fráncfort d.M.: Klostermann, 2005, p. 110, quien considera que la incumbencia no deriva de la norma en cuestión.

${ }^{32}$ En ese sentido, existiría siempre una norma "secundaria" de organizar de tal manera la propia libertad para que de ella no salgan peligros no susceptibles de ser dominados (RENZIKOWSKI, Restriktiver Täterbegriff, cit. nota $\mathrm{n}^{\mathrm{o}} 25$, p. 80). Aun sin pronunciarse sobre este tema, sino sobre el conocimiento de las normas para poder (in-)cumplirlas, MOLINA FERNÁNDEZ, Fernando, Antijuridicidad penal y sistema del delito, Barcelona: J.M. Bosch, 2001, p. 587, se refiere a que toda norma promulgada expresa indirectamente que "en estos casos el sujeto cargará con los eventuales perjuicios que se puedan derivar de su ignorancia".

${ }^{33}$ Cfr. BIEWALD, Regelgemäßes Verhalten und Verantwortlichkeit, cit. nota n ${ }^{\circ} 19$, p. 107.

${ }^{34}$ Uno de los aspectos más problemáticos (cfr. MONTIEL, "Obliegenheiten im Strafrecht?", cit. nota no 1, pp. 606-607) que he percibido para la aceptación de las incumbencias es la idea de que constituyen "obligaciones respecto a uno mismo" (así, en HRUSCHKA, Strafrecht, cit. nota ${ }^{\circ}$ 8, p. 416; KINDHÄUSER, Urs, Gefährdung als Straftat. Rechtstheoretische Untersuchungen zur Dogmatik der abstrakten und konkreten Gefährdungsdelikte, Fránkfort d.M.: Klostermann, 1989, p. 67), lo cual evoca deberes de contenido ético (por la autonomía que los caracteriza), o deberes no jurídicos (por la ausencia de alteridad). Sin embargo, eso no significa convertirlos en deberes carentes de juridicidad y relegarlos al ámbito meramente ético (cfr. supra, $\mathrm{n}$ 25): así, HRUSCHKA, Strafrecht, cit. nota no 8, p. 416, implícitamente. 
Polít. crim. Vol. 12, № 24 (Diciembre 2017), Art. 15, pp. 1211-1227.

[http://www.politicacriminal.cl/Vol_12/n_24/Vol12N24A15.pdf]

requiere $^{35}$ de un destinatario que se halle y se mantenga en condiciones de cumplirla: ii) las incumbencias de disposición, referidas a la actuación (ejercer la volición) y seguir la norma (con voluntariedad) ${ }^{36}$. Paralelamente, el contenido de sendas incumbencias podría rezar así: "si eres destinatario de una norma, preocúpate de conocer esta y las circunstancias del caso para saber cuál es tu deber" (i), "y procura mantenerte en disposición de poder cumplirlo" (ii), que constituirían el presupuesto de la incumbencia, como norma que es; al que seguiría su consecuencia (supra, 2.): "de lo contrario, se te imputará igualmente".

Con todo, esa dualidad de facetas de las incumbencias no puede dar a entender que se trata de fuentes totalmente diversas de imputación extraordinaria, es decir, de razones por las que se hace intolerable interrumpir la atribución de responsabilidad, pero radicalmente distintas entre sí. A mi modo de ver, pienso que no se trata de que existan incumbencias en paralelo a las exigencias de imputación ${ }^{37}$ : así, si para imputar se requiere conocimiento y volición (en el primer nivel o imputatio facti), en paralelo se presentarían las incumbencias de conocer y de querer, respectivamente; y si se requiere saber y voluntariedad (en el segundo nivel o imputatio iuris), también paralelamente las incumbencias de saber y de voluntariedad. Pienso que el planteamiento es más simple y no tan paralelo. Puede explicarse de manera más sencilla y menos mecánica

Al sujeto destinatario de normas incumbe concretar la norma en deber y no perder la capacidad de cumplirlo: respectivamente, las incumbencias de conocer y de disposición. Es decir, que le concierne o corresponde precisar el mensaje de la norma al caso, lo cual exige conocer la norma y los elementos fácticos de aplicación ${ }^{38}$; así como mantenerse en condiciones de poder obrar y de obrar conforme a deber. Pero estas incumbencias no comparecen secuencial y unidireccionalmente siguiendo el orden de la teoría del delito convencional, es decir, primero la de conocer los datos de hecho, a los que seguiría la volición; para luego considerar el saber sobre el significado jurídico de la conducta, a la que se añadiría la voluntariedad. El procedimiento intelectual de ideación del deber no comienza siempre necesariamente por el hacer presente la norma en la representación mental del sujeto, seguido de la indagación de las circunstancias fácticas, y una cuidadosa derivación de la conclusión. El procedimiento de ideación del concreto deber del agente puede iniciarse por el conocimiento tanto de los datos fácticos, como del sentido normativo de la acción; pero también en ocasiones proponiéndose primariamente el deber para cuyo cumplimiento se buscan las circunstancias fácticas idóneas. Con otras palabras: como sujeto destinatario de la norma, en ocasiones partimos de la prohibición abstracta ("no

\footnotetext{
${ }^{35}$ Para RENZIKOWSKI, Restriktiver Täterbegriff, cit. nota $\mathrm{n}^{\circ}$ 25, pp. 80, 230-231, es preciso asegurar la capacidad del sujeto para evitar eventuales resultados lesivos, es decir, garantizar la capacidad de prevenir los resultados que se requiera en cada caso.

${ }^{36}$ Sobre la distinción entre volición (,willentlich“) y voluntariedad (,freiwillig“), cfr. HRUSCHKA, Joachim, "Regreßverbot, Anstiftungsbegriff und die Konsequenzen", ZStW 110 (1998), pp. 581-610 (trad. SánchezOstiz, en: Imputación y Derecho penal, cit. nota $\mathrm{n}^{\circ}$ 14, pp. 169-195), pp. 581-639, 601-602; SÁNCHEZOSTIZ, Imputación y teoría del delito, cit. nota ${ }^{\circ} 1$, pp. 439-446.

${ }^{37}$ Sobre estas categorías, en el conjunto de la doctrina de la imputación, cfr. HRUSCHKA, Joachim, "Verhaltensregeln und Zurechnungsregeln", Rechtstheorie 22 (1991), pp. 449-460 (trad., Baldó, en Imputación y Derecho penal, cit. nota $\mathrm{n}^{\circ} 14$, pp. 27-39), pp. 449-460.

${ }^{38}$ Cfr. RENZIKOWSKI, Restriktiver Täterbegriff, cit. nota $\mathrm{n}^{\circ}$ 25, pp. 227, 231.
} 
SÁNCHEZ-OSTIZ, Pablo "Imputación e incumbencias en Derecho penal”.

mates", por ejemplo) como premisa mayor, que aplicamos al caso ("voy a disparar un arma, y X se halla en la trayectoria") como premisa menor, para llegar a la conclusión ("he de cesar en lo que estoy haciendo para evitar matar a X"). Pero en otras ocasiones comenzamos por los datos fácticos ("hay algo o alguien en la línea de tiro de esta arma"), y de ahí nos remontamos a la premisa mayor ("¿estará prohibido disparar?", "está prohibido matar") con el fin de valorar aquéllos, y decidirnos por un curso de acción como conclusión ("no disparo"). Y aun en otros casos comenzamos por la conclusión, objeto del deseo ("voy a evitar males para X, a quien estimo"), y lo concretamos en situaciones diversas ("me abstengo de crear cursos de riesgo contra X"), lo cual coincide con el mensaje de la norma ("y además resulta que matar, lesionar, coaccionar..., está prohibido"). En estas tres situaciones, el sujeto opera intelectualmente identificando elementos de juicio para tomar la decisión y moverse a actuar. Con otras palabras: en todas ellas está en juego el razonamiento práctico, para el cual resulta clave el aspecto prudencial o de ideación del deber para el caso ${ }^{39}$.

Podemos formular ahora con claridad que la incumbencia "precede" al deber y "sigue" a la norma; además, la incumbencia dependerá de cuál sea la norma a la que vienen a hacer operativa. Puesto que las normas no son expectativas garantizadas de forma automática, sino mediante decisiones (de cumplimiento y ejercicio) por su destinatario, se exige que éste extraiga y concrete el deber para su caso $^{40}$. Las incumbencias vienen a asegurar la eficacia de las normas, para lo cual se exige concretar tanto el contenido normativo (premisa mayor) como las condiciones de aplicabilidad (premisa menor) del silogismo práctico del agente destinatario de la norma, y sacar la conclusión ${ }^{41}$. Sin la incumbencia de conocer, tanto la norma como los datos fácticos, el mensaje normativo resultará inoperante, pues quedará en expresiones meramente descriptivas, sin "functor" deóntico posible (daría lo mismo afirmar "llueve" que " $¡$ no debes matar!"). Y sin la incumbencia de disposición, el mensaje normativo resultará ineficaz, pues el sujeto no adoptará los medios para actuar. En definitiva, una norma que no cuente con que el destinatario la concrete en deber en cuanto regla específica de acción, así como que se mantenga en condiciones de poder cumplirla, resultaría vana y fútil ${ }^{42}$. En efecto, si existen normas de conducta, debe garantizarse la

\footnotetext{
39 Así, las incumbencias de conocer y mantenerse en condiciones de cumplir los deberes son cargas que corresponden al agente como persona. En este sentido, para GÜNTHER, Schuld und kommunikative Freiheit, cit. nota $\mathrm{n}^{\circ}$ 31, pp. 110-111, la incumbencia se refieren al concepto de persona en Derecho; y para PAWLIK, Michael, Person, Subjekt, Bürger. Zur Legitimation von Strafe, Berlín: Duncker \& Humblot, 2004, pp. 84-87, la incumbencia enlazaría con el fundamento de la imputación al "ciudadano".

${ }^{40}$ Para HRUSCHKA, Strafrecht, cit. nota ${ }^{\circ}$ 8, p. 417, ,die Obliegenheiten als diejenigen Gebote und Verbote [...], deren Verletzung, obwohl sie nicht als solche bestraft wird, doch eine Bedingung für de Möglichkeit ist, die Strafbarkeit der Verletzung einer - von der Obliegenheit zu unterscheidenden - Pflicht anzunehmen." En este sentido, la infracción de un deber llevará consigo antes la de una incumbencia. Pero en tal caso es la del deber lo que sancionamos, y solo nos preocupamos cuando eso no fuera posible por un defecto de imputación. Es ahí cuando la infracción de la incumbencia pasa a primera línea para restablecer la imputación.

${ }^{41}$ De este modo, es a través del silogismo práctico como se llega a la ideación de la norma: cfr. v. WRIGHT, Georg Henrik, La diversidad de lo bueno (orig., 1963, trad., González Lagier/Roca), Madrid: Marcial Pons, 2010, pp. 183-186, 189-194.

${ }^{42}$ Véanse los planteamientos de KINDHÄUSER, Gefährdung als Straftat, cit. nota $\mathrm{n}^{\circ}$ 34, pp. 132-136; VOGEL, Joachim, Norm und Pflicht bei den unechten Unterlassungsdelikten, Berlín: Duncker \& Humblot,
} 
Polít. crim. Vol. 12, № 24 (Diciembre 2017), Art. 15, pp. 1211-1227.

[http://www.politicacriminal.cl/Vol_12/n_24/Vol12N24A15.pdf]

posibilidad de cumplirlas, dado que es propio de la norma que se cumpla por decisión del destinatario $^{43}$. Así, puede decirse que pertenece a la constitución racional del destinatario (dotado de racionalidad práctica) concretar la norma en deber para el caso singular (silogismo práctico) $)^{44}$, y ordenarse a sí mismo a actuar en cada situación singular. Y todo imperativo parte del carácter racional del destinatario, quien goza de libertad hasta donde surja el deber, pero a quien también atañe extraer el deber y mantenerse en condiciones de poder cumplirlo cuando surja la situación ${ }^{45}$. Dicho de otro modo: en medio de la libertad general de actuación de que goza el destinatario de las normas, se cuenta también con que podrá cumplir, llegado el caso, los respectivos deberes.

\section{Diferencias entre las incumbencias y otras categorías}

Este modo de entender las incumbencias hace que se evidencien las diferencias entre esta categoría y otras que empleamos habitualmente en la dogmática jurídico-penal. En concreto, me refiero a tres categorías que juegan ya un relevante papel en la teoría del delito: el deber de cuidado, la competencia, y la obligación o deber de conocer las normas. A su vez, se muestran con claridad las diferencias entre los conceptos de incumbencia y de deber.

Por lo que hace al deber de cuidado 46 , en primer lugar, la categoría de la imputación extraordinaria posibilita restablecer la imputación y afirmar que el sujeto es artífice de un hecho (imputatio facti); después procede la imputación de segundo nivel o imputatio iuris,

1993, pp. 36-37; MOLINA FERNÁNDEZ, Antijuridicidad penal, cit. nota $\mathrm{n}^{\circ}$ 32, pp. 614-619, 643; MAÑALICH, Nötigung und Verantwortung, cit. nota $\mathrm{n}^{\circ}$ 1, p. 67.

${ }^{43}$ Por lo tanto, la cuestión no es la de la derivación de las incumbencias desde la norma de conducta (cfr. esta problemática en NEUMANN, "Normtheorie und strafrechtliche Zurechnung", cit. nota $n^{\circ}$ 8, p. 395), sino de que toda norma de conducta ha de entenderse -si tiene expectativas de vigencia- como mensaje a recibir y concretar por su destinatario. En este sentido, entiendo que la existencia de las incumbencias sería de orden analítico (pertenece al concepto mismo de norma), mientras que la concreta conducta a que da lugar es de carácter sintético (depende de cada situación del agente).

${ }^{44}$ Para BINDING, Karl, Die Normen und ihre Übertretung, vol. I, $4^{\text {a }}$ ed., Leipzig, 1922; reimpr., Aalen: Scientia, 1991, p. 110, la prohibición no solo expresa conductas a evitar, sino a la vez también un mandato de obrar con cuidado, como precepto secundario, no independiente de la prohibición primaria („Gebot des sorgsamen Handelns”, y que luego calificaría como deber de atención, „Aufmerksamkeitspflicht”), que no es un mandato independiente, sino parte del deber fundado en la norma (Die Normen, II-1, 2. ${ }^{a}$ ed, p. 241). Y añade: ,so ist die sorgfältige Überlegung vor und während der Tat das einzige Mittel ihr die Rechtmässigkeit zu wahren" (Die Normen, II-1, p. 236), en virtud de dicho deber de atención. Más allá de concebir ese deber de atención como una incumbencia -que no es mi posición-, entiendo muy revelador que Binding haya asociado los dos mensajes normativos.

${ }^{45}$ Cfr. MAÑALICH, Juan Pablo, Norma, causalidad y acción. Una teoría de las normas para la dogmática de los delitos de resultado puros, Madrid: Marcial Pons, 2014, p. 134, nota 148; MAÑALICH, Nötigung und Verantwortung, cit. nota $\mathrm{n}^{\circ} 1$, p. 70 , si bien considerando al destinatario de la norma como persona fiel al Derecho.

${ }^{46}$ Para HRUSCHKA, Strafrecht, cit. nota $\mathrm{n}^{\circ} 8$, p. 418, hay que mantener separados los conceptos de (infracción de una) incumbencia y de (infracción de un) deber, sobre todo en sede de imprudencia (por el deber de cuidado). En contra de atender a la figura de incumbencias, y atendiendo en cambio al deber de cuidado, FEIJOO SÁNCHEZ, Bernardo, Resultado lesivo en imprudencia, Barcelona: J.M. Bosch, 2001, p. 304, n 907; y CUELLO CONTRERAS, Joaquín, El Derecho penal español. Parte general. Nociones introductorias. Teoría del delito, Madrid: Dykinson, 2002, XI/170. 
SÁNCHEZ-OSTIZ, Pablo "Imputación e incumbencias en Derecho penal”.

para reprocharle al agente haber realizado un hecho antijurídico ${ }^{47}$. Una vez imputado de manera extraordinaria un proceso como hecho, es decir, a pesar del defecto de imputación, entrará en juego el "deber de cuidado". Recurrimos a esta idea para valorar o medir el hecho como típicamente antijurídico a los efectos del precepto del delito (imprudente) ${ }^{48}$ en cuestión; y seguirá después, en su caso, la imposición de una sanción, cuestión que conviene mantener separada de la imputación del hecho por vía extraordinaria, y por tanto de la incumbencia. De este modo, la incumbencia opera para restablecer la imputación del hecho, que luego se valora con arreglo al deber de cuidado respectivo -y entonces, si, por ejemplo, el resultado producido no estaba abarcado por el fin de la "norma" en cuestión, el hecho será atípico ${ }^{49}$. Este modo de proceder no puede pasar por alto que, para afirmar que se ha realizado un hecho típico, primero se requiere un hecho: en definitiva, incumbencia y deber de cuidado cumplen funciones diversas.

En segundo lugar, respecto al concepto de competencia también hay diferencias. Si por competencia se entiende la situación normativa del agente en relación a la víctima, terceros y desde su propia posición institucional, hay algunos puntos de conexión. Pero también diferencias. En concreto, a mi modo de ver, la competencia opera como un concepto estático sobre lo que al agente corresponde realizar u omitir, mientras que la incumbencia hace referencia a un concepto dinámico, el proceso racional de determinación de la concreta regla de acción. Obviamente, puede operar la competencia como fuente de las cargas que corresponden al agente, precisamente por su situación respecto a la víctima, terceros y su propia posición institucional, pero se refiere a un aspecto distinto del que tomamos en cuenta en las incumbencias.

Y en tercer lugar, por lo que hace a la obligación de conocer el Derecho, puede resultar contradictorio otorgar relevancia al desconocimiento de la antijuricidad a la vez que se apela a una obligación de conocer ${ }^{50}$. Pero lo cierto es que allá donde la legislación prevé una atenuación -sea facultativa, sea preceptiva- para los casos de error vencible, se hace necesario contar con criterios de vencibilidad o no de dicho error. Recurrir a un deber de informarse sobre el contenido de las leyes resulta problemático ${ }^{51}$, por lo que se busca una base normativa distinta ${ }^{52}$. Sin embargo, es difícil evitar un elemento de obligación, que no

\footnotetext{
${ }^{47}$ Cfr. nota 37.

${ }^{48}$ Cfr. nota 23.

${ }^{49}$ Por tanto, la incumbencia no resuelve más que un primer problema para la responsabilidad (que se pueda imputar el proceso como un hecho), y luego es preciso considerar su tipicidad. MAÑALICH, Nötigung und Verantwortung, cit. nota $\mathrm{n}^{\mathrm{o}} 1$, p. 72, plantea que existan incumbencias primarias y secundarias.

${ }^{50}$ Cfr. JAKOBS, Günther, Studien zum fahrlässigen Erfolgsdelikten, Berlín: Gruyter, 1972, pp. 13-15.

51 Así, para JESCHECK, Hans-Heinrich; WEIGEND, Theodor, Lehrbuch des Strafrechts. Allgemeiner Teil, 5. a ed, Berlín: Duncker \& Humblot, 1996, 41/II.2.b, en algunos casos el deber de información se deriva del dolo del tipo, en la medida en que, según la experiencia, existan preceptos jurídicos en ese sector. Ciertamente recurrir a un deber de conocer no resulta fácil (cfr. en ROXIN, Claus, Strafrecht. Allgemeiner Teil. Grundlagen. Der Aufbau der Verbrechenslehre, I, $4^{a}$ ed., Múnich: C.H. Beck, 2006, § 21/35-37, las críticas al planteamiento del deber de informarse o de conocer).

52 Así, en elementales reglas éticas (JESCHECK/WEIGEND, Lehrbuch, cit. nota $\mathrm{n}^{\circ}$ 50, 41/II.2.b), en la competencia del sujeto (JAKOBS, Strafrecht, 19/35, cit. nota ${ }^{\circ}$ 2; PAWLIK, Das Unrecht des Bürgers, cit. nota $\mathrm{n}^{\circ} 6$, pp. 329-333, 353-357), o en la irracionalidad de la excusa para responder cuando se ha provocado el defecto (NEUMANN, Ulfrid, Zurechnung und „Vorverschulden“. Vorstudien zu einem dialogischen
} 
Polít. crim. Vol. 12, № 24 (Diciembre 2017), Art. 15, pp. 1211-1227.

[http://www.politicacriminal.cl/Vol_12/n_24/Vol12N24A15.pdf]

puede identificarse, por débil que sea, con el mensaje mismo de la norma que se desconoce; y no cabe plantearlo como algo totalmente ajeno a esta norma ${ }^{53}$. Una manera de mantener ese presupuesto normativo del reproche por el desconocimiento, sin asimilarlo al conocimiento mismo de la norma, es la imputación extraordinaria y la incumbencia de conocer. Esto permite no confundir el mensaje de la norma con la incumbencia de concretarla en deber que atañe al destinatario.

A mi modo de ver, las incumbencias se distinguen de otras reglas de conducta como los "deberes" 54 , porque en aquellas el presupuesto queda indeterminado (pero no deja de existir; y por eso no se trata de "principios"); está, además, y en manos del destinatario identificar los datos fácticos que pueden hacer que el deber sea operativo, así como los detalles de contenido de la norma y la conexión de ésta al caso, y mantenerse en condiciones (en disposición) de cumplir el deber cuando llegue el momento concreto de llevarlo a cabo. Es decir, que le atañe precisar el deber concreto que sobre él recae. Por tanto, la operatividad de las incumbencias es funcional: sirven a los fines de la concreción de la norma en deber (y permisión) ${ }^{55}$ en el caso singular. Lo cual se diversifica en dos direcciones: por un lado, incumbe al destinatario conocer tanto los datos fácticos ("tengo delante a una persona y no un animal"), como los contenidos normativos ("está prohibido matar a otro"), que son condiciones de aplicabilidad de la norma ("iprohibido matar!") en el caso concreto: es decir, el paso de la premisa mayor a la conclusión a través de la premisa menor. Y por otro, le incumbe también mantenerse en disposición de poder cumplir el deber ejerciendo la voluntad tanto para actuar (evitando la pérdida de control y ejerciendo la volición), como para actuar motivadamente por la norma conocida (evitando perder la voluntariedad requerida para seguir el deber).

Una segunda diferencia entre deber e incumbencia reside en que el cumplimiento del primero puede exigirse directa (cabe legítima defensa frente al destinatario que lo

\footnotetext{
Modell strafrechtlicher Zurechnung, Berlín: Duncker \& Humblot, 1985, p. 269; NEUMANN, Ulfrid, "Neue Entwicklungen im Bereich der Argumentationsmuster zur Begründung oder zum Ausschluß strafrechtlicher Verantwortlichkeit", ZStW 99 (1987), pp. 567-594, 584-585; críticamente, GONZÁLEZ-RIVERO, Pilar, Strafrechtliche Zurechnung bei Defektzuständen. Zugleich ein Beitrag zur allgemeinen Zurechnungslehre, Berlín: Duncker \& Humblot, 2001, pp. 87-90).

${ }^{53}$ Sobre la capacidad de conocer el deber, cfr. KAUFMANN, Armin, Lebendiges und Totes in Bindings Normentheorie. Normlogik und moderne Strafrechtsdogmatik, Gotinga: Schwartz, 1954, pp. 163-169, en donde se expresa que la norma puede conocerse previamente, y entonces es cuestión de actualizar dicho conocimiento en el momento del hecho, o bien puede hacerse presente por derivación realizada por el propio sujeto, "Selbstableitung" (pp. 165-167). En el planteamiento de Kaufmann no resulta fácil recurrir a la idea de un deber de conocer la norma, pues aquel sigue a esta (en pp. 131, 138-140).

${ }^{54}$ Respecto a la distinción entre deber e incumbencia (y entre infracción del deber y de la incumbencia), cfr. HRUSCHKA, Strafrecht, cit. nota $\mathrm{n}^{\circ}$ 8, pp. 415-419; JOERDEN, Jan, Strukturen des strafrechtlichen Verantwortlichkeitsbegriffs: Relationen und ihre Verkettungen, Berlín: Duncker \& Humblot, 1988, p. 46, ${ }^{\circ}$ 104; KINDHÄUSER, Gefährdung, cit. nota no 34, pp. 65-83; KINDHÄUSER, Urs, "Zur Rechtfertigung von Pflicht- und Obliegenheitsverletzungen im Strafrecht”, JRE 2 (1994), pp. 339-351, 345; RUDOLPH, Das Korrespondenzprinzip im Strafrecht, cit. nota $\mathrm{n}^{\mathrm{o}}$ 19, pp. 84-90. Hacen eco del concepto, entre otros, GÜNTHER, Schuld und kommunikative Freiheit, cit. nota $\mathrm{n}^{\circ}$ 31, pp. 109-110; DUTTGE, Gunnar, Zur Bestimmtheit des Handlungsunwerts von Fahrlässigkeitsdelikten, Tubinga: Mohr Siebeck, pp. 84-87.

${ }^{55}$ Cfr. nota ${ }^{\circ} 30$.
} 
SÁNCHEZ-OSTIZ, Pablo "Imputación e incumbencias en Derecho penal".

incumpla, por ejemplo) o indirectamente (ante los órganos de la Administración de Justicia, por ejemplo), mientras que el de la incumbencia no es directa o indirectamente exigible hasta que se materialice en el momento de cumplir el deber. Puede recordarle la carga de reflexionar, poner atención o informarse..., pero eso no convierte la incumbencia en deber. Así, una señal de atención (“' Cuidado!") no es una incumbencia, sino la llamada a ejercer la incumbencia por aquel a quien le concierne, el agente.

Además, una tercera diferencia consiste en que la infracción del deber es sancionable, pues la consecuencia de su infracción es la pena prevista para el caso, mientras que la consecuencia de infringir la incumbencia será el restablecimiento de la imputación (cfr. supra, 2.), lo cual posibilita a continuación proseguir en su caso con la valoración del hecho como contrario a deber (al menos en las prohibiciones y mandatos) o con la imputación a título de reproche (como culpable).

El objetivo de esta contribución era plantear la conveniencia de atender en la dogmática jurídico-penal, junto a las normas y deberes, también a las incumbencias. Si he conseguido el objetivo que me proponía es cuestión que debe juzgar el lector, a quien le incumbe valorar la situación y obrar en consecuencia. 
Polít. crim. Vol. 12, No 24 (Diciembre 2017), Art. 15, pp. 1211-1227.

[http://www.politicacriminal.cl/Vol_12/n_24/Vol12N24A15.pdf]

\section{BIBLIOGRAFÍA}

AST, Stephan, Normentheorie und Strafrechtsdogmatik. Eine Systematisierung von Normarten und deren Nutzen für Fragen der Erfolgszurechnung, insbesondere die Abgrenzung des Begehungs- vom Unterlassungsdelikt, Berlín: Duncker \& Humblot, 2010.

BIEWALD, Günther, Regelgemäßes Verhalten und Verantwortlichkeit. Eine Untersuchung der Retterfälle und verwandter Konstellationen, Berlín: Duncker \& Humblot, 2003.

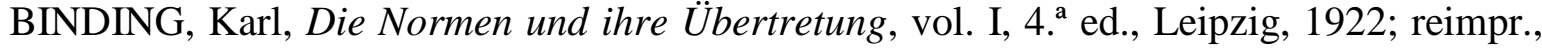
Aalen: Scientia, 1991.

, Die Normen und ihre Übertretung, II-1, 2. ${ }^{\mathrm{a}}$ ed., Leipzig, 1914; reimpr., Aalen: Scientia, 1991.

COCA VILA, Ivó, “¿Programas de Cumplimiento como forma de autorregulación regulada?”, en: SILVA SÁNCHEZ, Jesús-María (Dir.); MONTANER FERNÁNDEZ, Raquel (Coord.), Criminalidad de empresa y Compliance. Prevención y reacciones corporativas, Barcelona: Atelier, 2013, pp. 43-72.

CUELLO CONTRERAS, Joaquín, El Derecho penal español. Parte general. Nociones introductorias. Teoría del delito, Madrid: Dykinson, 2002.

DUTTGE, Gunnar, Zur Bestimmtheit des Handlungsunwerts von Fahrlässigkeitsdelikten, Tubinga: Mohr Siebeck, 2001.

FEIJOO SÁNCHEZ, Bernardo, Resultado lesivo en imprudencia, Barcelona: J.M. Bosch, 2001.

FRISCH, Wolfgang, Tatbestandsmäßiges Verhalten und Zurechnung des Erfolgs, Heidelberg: C.F. Müller, 1988.

, "Grundprobleme der Bestrafung, ,verschuldeter" Affekttaten. Eine dogmatische Zwischenbilanz aus Anlaß neuerer Entwicklungen”, ZStW 101 (1989), pp. 538-610.

GONZÁLEZ-RIVERO, Pilar, Strafrechtliche Zurechnung bei Defektzuständen. Zugleich ein Beitrag zur allgemeinen Zurechnungslehre, Berlín: Duncker \& Humblot, 2001.

GÜNTHER, Klaus, Schuld und kommunikative Freiheit. Studien zur personalen Zurechnung strafbaren Unrechts im demokratischen Rechtsstaat, Fráncfort d.M.: Klostermann, 2005.

HAAS, Volker, Kausalität und Rechtsverletzung. Ein Beitrag zu den Grundlagen strafrechtlicher Erfolgshaftung am Beispiel des Abbruchs rettender Kausalverläufe, Berlín: Duncker \& Humblot, 2002.

HÖRNLE, Tatjana, ,Die Obliegenheit, sich selbst zu schützen, und ihre Bedeutung für das Strafrecht", GA 2009, pp. 626-635.

HRUSCHKA, Joachim, "Über Tun und Unterlassen und über Fahrlässigkeit", en: KAUFMANN, Arthur et al. (Eds.), Festschrift für Paul Bockelmann zum 70. Geburtstag, Múnich: Beck, 1979, pp. 421-436.

"Ordentliche und außerordentliche Zurechnung bei Pufendorf. Zur Geschichte und zur Bedeutung der Differenz von actio libera in se und actio libera in sua causa", ZStW 96 (1984), pp 661-702 (trad., Pastor Muñoz, en: Imputación y Derecho penal, ed. a cargo de Pablo Sánchez-Ostiz, Cizur Menor (Navarra): Thomson-Aranzadi, 2005, pp. 55-88), pp. 661-702. 
SÁNCHEZ-OSTIZ, Pablo "Imputación e incumbencias en Derecho penal".

Strafrecht nach logisch-analytischer Methode, $2^{\mathrm{a}}$ ed., Berlín, Nueva York: Gruyter, 1988.

, "Verhaltensregeln und Zurechnungsregeln", Rechtstheorie 22 (1991), pp. 449-

460 (trad., Baldó, en: Imputación y Derecho penal. Estudios sobre la teoría de la imputación, ed. a cargo de Pablo Sánchez-Ostiz, Cizur Menor (Navarra): ThomsonAranzadi, 2005, pp. 27-39).

, "Regreßverbot, Anstiftungsbegriff und die Konsequenzen", ZStW 110 (1998), pp. 581-610 (trad. Sánchez-Ostiz, en: Imputación y Derecho penal. Estudios sobre la teoría de la imputación, ed. a cargo de Pablo Sánchez-Ostiz, Cizur Menor (Navarra): Thomson-Aranzadi, 2005, pp. 169-195).

HÜBNER, Christoph, Die Entwicklung der objektiven Zurechnung, Berlín: Duncker \& Humblot, 2004.

JAKOBS, Günther, Studien zum fahrlässigen Erfolgsdelikten, Berlín: Gruyter, 1972. , Strafrecht. Allgemeiner Teil. Die Grundlagen und die Zurechnungslehre, 2. ${ }^{a}$ ed., Berlín, Nueva York: Gruyter, 1991. , System der strafrechtlichen Zurechnung, Fráncfort d.M.: Klostermann, 2012. , Theorie der Beteiligung, Tubinga: Mohr Siebeck, 2014.

JESCHECK, Hans-Heinrich; WEIGEND, Theodor, Lehrbuch des Strafrechts. Allgemeiner Teil, 5a ed., Berlín: Duncker \& Humblot, 1996.

JOERDEN, Jan, Strukturen des strafrechtlichen Verantwortlichkeitsbegriffs: Relationen und ihre Verkettungen, Berlín: Duncker \& Humblot, 1988.

KAUFMANN, Armin, Lebendiges und Totes in Bindings Normentheorie. Normlogik und moderne Strafrechtsdogmatik, Gotinga: Schwartz, 1954.

KINDHÄUSER, Urs, Gefährdung als Straftat. Rechtstheoretische Untersuchungen zur Dogmatik der abstrakten und konkreten Gefährdungsdelikte, Fránkfort d.M.: Klostermann, 1989.

, "Zur Rechtfertigung von Pflicht- und Obliegenheitsverletzungen im Strafrecht", JRE 2 (1994), pp. 339-351.

MAÑALICH, Juan Pablo, Nötigung und Verantwortung. Rechtstheoretische Untersuchungen zum präskriptiven und adskriptiven Nötigungsbegriff im Strafrecht, Baden-Baden: Nomos, 2009.

, Norma, causalidad y acción. Una teoría de las normas para la dogmática de los delitos de resultado puros, Madrid: Marcial Pons, 2014.

MONTIEL, Juan Pablo,“Obliegenheiten im Strafrecht?”, ZStW 129 (2014), pp. 592-614. $1-29$. “¿Existen las Obliegenheiten en el Derecho penal?”, InDret Penal 4/2014, pp.

MOLINA FERNÁNDEZ, Fernando, Antijuridicidad penal y sistema del delito, Barcelona: J.M. Bosch, 2001.

NEUMANN, Ulfrid, "Normtheorie und strafrechtliche Zurechnung", GA 1985, pp. 389401.

, Zurechnung und „Vorverschulden“. Vorstudien zu einem dialogischen Modell strafrechtlicher Zurechnung, Berlín: Duncker \& Humblot, 1985.

, "Neue Entwicklungen im Bereich der Argumentationsmuster zur Begründung oder zum Ausschluß strafrechtlicher Verantwortlichkeit”, ZStW 99 (1987), pp. 567594. 
Polít. crim. Vol. 12, No 24 (Diciembre 2017), Art. 15, pp. 1211-1227.

[http://www.politicacriminal.cl/Vol_12/n_24/Vol12N24A15.pdf]

PAWLIK, Michael, Person, Subjekt, Bürger. Zur Legitimation von Strafe, Berlín: Duncker \& Humblot, 2004.

, Das Unrecht des Bürgers. Grundlinien der Allgemeinen Verbrechenslehre, Tubinga: Mohr Siebeck, 2012.

PHILIPPS, Lothar, "Normentheorie", en: KAUFMANN, Arthur; HASSEMER, Winfried: NEUMANN, Ulfrid (Eds.), Einführung in Rechtsphilosophie und Rechtstheorie der Gegenwart, $7^{\mathrm{a}}$ ed., Heidelberg: Müller, 2004, pp. 320-332.

RENZIKOWSKI, Joachim, Restriktiver Täterbegriff und fahrlässige Beteiligung, Tubinga: Mohr Siebeck, 1997.

ROBLES PLANAS, Ricardo, "El "hecho propio" de las personas jurídicas y el Informe del Consejo General del Poder Judicial al Anteproyecto de Reforma del Código Penal de 2008", InDret Penal 2/2009, pp. 1-12.

, Estudios de dogmática jurídico-penal. Fundamentos, teoría del delito y Derecho penal económico, Montevideo, Buenos Aires: BdeF, 2014.

ROSTALSKI, Frauke, "Normentheorie und Fahrlässigkeit. Zur Fahrlässigkeit als Grundform des Verhaltensnormverstoßes", GA 2016, pp. 73-89.

ROXIN, Claus, Strafrecht. Allgemeiner Teil. Grundlagen. Der Aufbau der Verbrechenslehre, I, $4^{\mathrm{a}}$ ed., Múnich: Beck, 2006.

RUDOLPH, Tobias, Das Korrespondenzprinzip im Strafrecht. Der Vorrang von ex-ante Betrachtungen gegenüber ex-post Betrachtungen bei der strafrechtlichen Zurechnung, Berlín: Duncker \& Humblot, 2006.

SÁNCHEZ-OSTIZ, Pablo, "Existencia y operatividad de las incumbencias jurídicopenales", en: CARNEVALI RODRÍGUEZ, Raúl (Ed.), Derecho, sanción y justicia penal, Montevideo, Buenos Aires: BdeF, 2017, pp. 41-59. , “Incumbencias en Derecho penal? .-Depende”, InDret Penal 1/2015, pp. 1-27. , La libertad del Derecho penal y otros estudios sobre la doctrina de la imputación, Barcelona: Atelier, 2014.

, Imputación y teoría del delito. La doctrina kantiana de la imputación y su recepción en el pensamiento jurídico-penal contemporáneo, Montevideo, Buenos Aires, BdeF: 2008.

SEEBAß, Gottfried, "Handlungstheoretische Aspekte der Fahrlässigkeit", JRE 2 (1994), pp. 375-411.

TOEPEL, Friedrich, Kausalität und Pflichtwidrigkeitszusammenhang beim fahrlässigen Erfolgsdelikt, Berlín: Duncker \& Humblot, 1992.

VOGEL, Joachim, Norm und Pflicht bei den unechten Unterlassungsdelikten, Berlín: Duncker \& Humblot, 1993.

WRIGHT, Georg Henrik von, La diversidad de lo bueno (orig., 1963, trad., González Lagier/Roca), Madrid: Marcial Pons, 2010.

WOLTER, Jürgen, Objektive und personale Zurechnung von Verhalten, Gefahr und Verletzung in einem funktionalen Straftatsystem, Berlín: Duncker \& Humblot, 1981. 